\title{
Study on the Servo Drive of PM-LSM to Be Used in Parallel Synchronous Drive
}

\author{
Hiroyuki Takai, Suzuki Kenji, and Hideo Dohmeki \\ Department of Electrical and Electronic Engineering, Tokyo City University, Tokyo 158-8557, Japan
}

\begin{abstract}
Recently, linear motors can have high speed control, high acceleration-deceleration. So linear motors are widely used in industrial applications such as precision machine tools. In our laboratory focusing on transport system, we propose parallel synchronous drive of used the PM-LSM (permanent magnet linear synchronous motor). It can pass luggage without having to stop the working. When you establish "parallel synchronous drive", a motor follows the other motor. In our laboratory, one of the motors is called "master motor" and the other motor called "slave motor". The master motor's speed and position pass slave motor then establish parallel synchronous drive. Therefore, slave motor requires high-responsive and precision that follows the master motor. This paper focuses on the control of the slave motor.
\end{abstract}

Key words: PM-LSM, master-slave motor, PI control, parallel synchronous drive method.

\section{Introduction}

The LIM (linear induction motor) is used as the power source of long-distance conveyance system and has been extensively studied because of its simple structure [1-3]. Because of the drive principle, intermittence of the primary side is easy and the cost is decreased $[1,2]$.

Recently, permanent magnet type linear motors (PM-LSM) can have high speed control and high acceleration-deceleration. So linear motors are widely used in industrial applications such as precision machine tools. Our laboratory focuses on conveyance system [4]. Usually, an initial cost of PM-LSM rises to employ a full-length stator-side-on-ground design. Thus our laboratory has proposed an ISPM-LSM (intermittent stator PM-LSM) [5-9]. This system arranges the stator intermittently. The quantity of the stator decreases. And the section changing the method of the stator is proposed as this driving method [10]. Because the runway has a high degree of freedom on the bounty of non-stator area, it is possible to realize the corner part. However, in each processing area,

Corresponding author: Hiroyuki Takai, M.Sc., research field: linear motors control and drive. when the conveyance material pulls down from the mover, it is necessary to repeat "stop and go" the mover. This work leads to a reduction of transport efficiency.

Therefore, we propose parallel synchronous drive [11]. This method synchronizes the mover of the two LSMs. One assumes the main-line connecting the inter-processes and the other assumes the sub-line of each processing. Because both movers in the synchronized state have the same inertia, conveyance material may be moved without the mover stops. Main line of the motor is called "master motor" and the other motor is called "slave motor". The master motor's speed and position pass slave motor then establish parallel synchronous drive.

In this paper, we focus on the control of the slave motor. Control of the motor is verified by using the experimental apparatus.

\section{Composition of Experimental Device}

\subsection{Concept of Parallel Synchronous Drive Method}

The concept of the long-distance conveyance system in a factory is shown in Fig. 1. Generally, product processing in a factory differs in area for every process, and moves between each process at high speed. When 


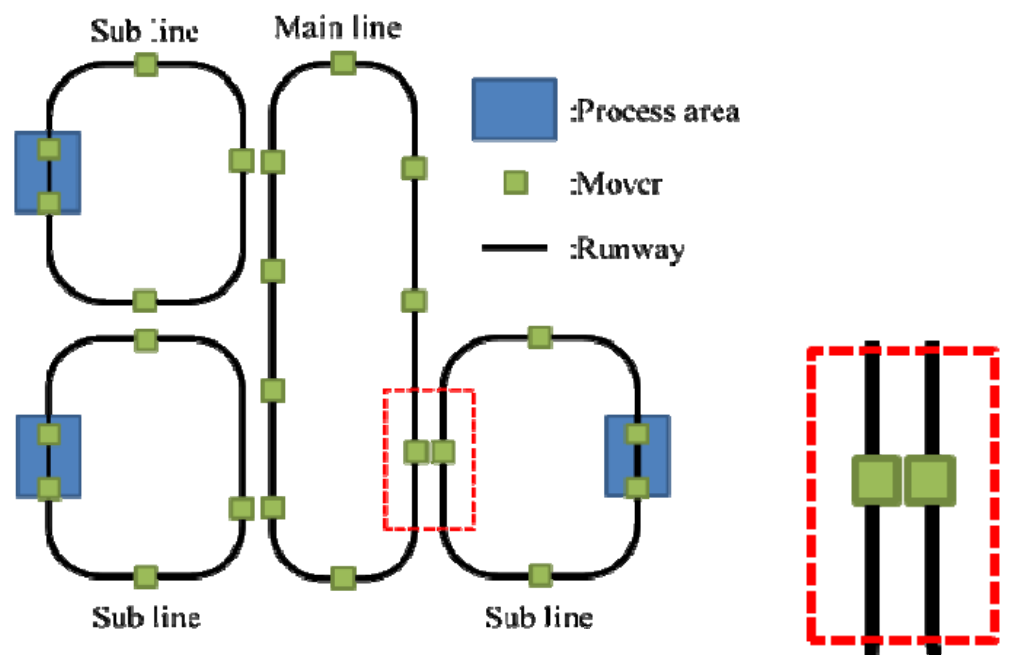

(a) Transport system for long distance

(b) Parallel synchronous drive

Fig. 1 Transport system.

transferring the conveyance material to the line of each processing from the conveyor line, it is required to operate in "ride-down" on having stopped the mover. For repeating this drive, it cannot be expected efficiency of the conveyance.

Therefore, as shown in Fig. 1b, to set up a sub-line (slave) of each process in parallel with the main line (master), the mover of the two lines parallel synchronous drive, without stopping the mover can move the conveyance material. Thus, by this method, the conveyance efficiency is improved remarkably.

\subsection{Construction and Specifications of Experimental Device}

Parallel synchronous drive needs two linear motors, one linear motor is the master-side, and it moves in the stator intermittent placement.

The other linear motor is slave-side and it moves the stator continuous placement. When keeping freely moving the master motor, then passing the master date to the slave motor, therefore slave motor can follow to the master motor. Slave motor controlled by PI (proportional integral) control. Fig. 2 shows the configuration of the master-side experiment equipment. The outline of experimental device at master side is shown in Fig. 1. Fig. 3 is the experimental apparatus of ISPM-LSM that assumes the main line of the transport system. The master side has a configuration which is arranged to intermittently stator. Table 1 shows the specifications used for the simulation model in. Fig. 4 shows the configuration of the slave-side experiment equipment. The outline of experimental device at slave side is shown in Fig. 5. In addition, Fig. 5 is the experimental apparatus of PM-LSM that assumes the sub line of the transport system. Slave motor is the experimental apparatus mainly used in this paper.

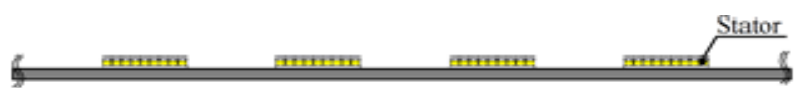

Fig. 2 Master motor (stator intermittent placement).

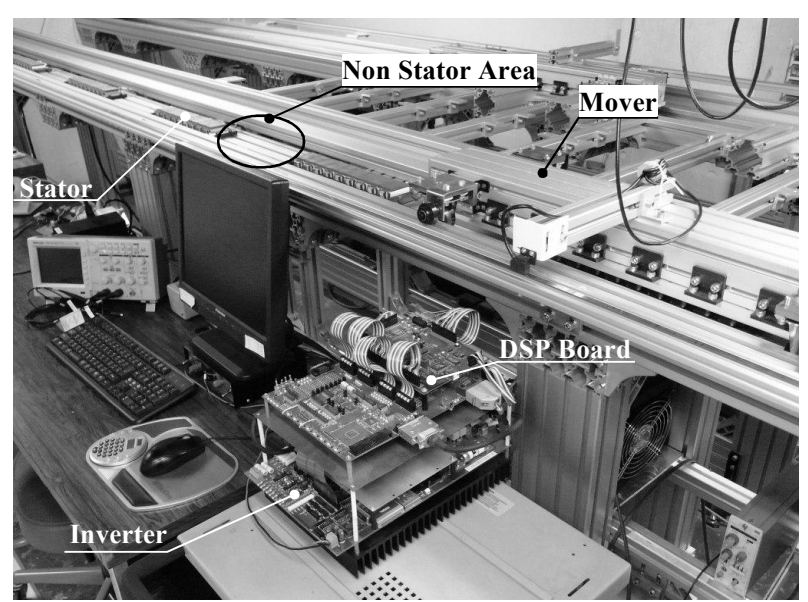

Fig. 3 An outline of experimental device of master side. 
Table 1 Specification of the experimental device of master side.

\begin{tabular}{lc|c}
\hline \multicolumn{1}{c|}{ Item } & Value(Unit) \\
\hline \hline Stator of Master & & \\
\hline Number of slot & $S_{M}$ & $9($ Slots $)$ \\
\hline Armature resistance & $R_{a M}$ & $1.55(\Omega)$ \\
\hline Inductance(overlap) & $L_{a M}$ & $53.0(\mathrm{mH})$ \\
\hline Inductance(non-overlap) & $L_{a{ }_{M}}{ }^{\prime}$ & $39.3(\mathrm{mH})$ \\
\hline Length of Stator(per unit) & $l_{s M}$ & $360(\mathrm{~mm})$ \\
\hline Secondary Mover of Master & & \\
\hline Number of Magnet & $P_{M}{ }^{\prime}$ & $28(\mathrm{Pieces})$ \\
\hline Number of pole & $P_{M}$ & $12(\mathrm{Poles})$ \\
\hline Pole Pitch & $\tau_{p}$ & $30(\mathrm{~mm})$ \\
\hline Mass of Secondary mover & $M_{M}$ & $20(\mathrm{~kg})$ \\
\hline Length of Secondary mover & & $900(\mathrm{~mm})$ \\
\hline Thrust Constant & $K_{f M}$ & $29.6(\mathrm{~N} / \mathrm{A})$ \\
\hline Induced voltage Constant & $K_{e M}$ & $9.86(\mathrm{~V} / \mathrm{m} / \mathrm{s})$ \\
\hline Non-stator Area & $g^{\prime}{ }_{s}$ & $420(\mathrm{~mm})$ \\
\hline Air-gap & $g$ & $6.0(\mathrm{~mm})$ \\
\hline
\end{tabular}

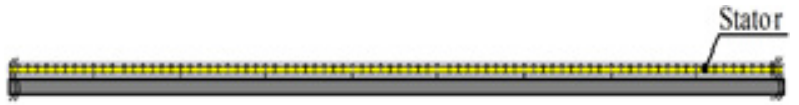

Fig. 4 Slave motor (stator continuous placement).

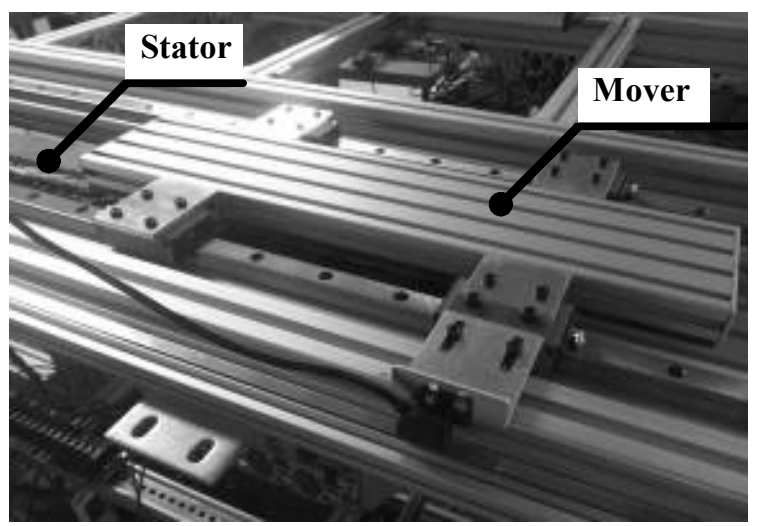

Fig. 5 An outline of experimental device of slave side.

\section{Results of PI Control of Slave Motor}

Speed and current of the slave motor is controlled by PI control. The block diagram of the PI control is shown in Fig. 6 (Lp means the linear pulses from the magnet encoder). Internal structure of the current controller is a dq coordinate system. Command speed of the slave motor of this experiment is virtually entering the speed of the master motor. Command speed is acceleration and deceleration control of up to $0-0.5 \mathrm{~m} / \mathrm{s}$.
Table 2 Specification of the experimental device of slave side.

\begin{tabular}{lc|c}
\hline \multicolumn{1}{c|}{ Item } & Value (Unit) \\
\hline \hline Stator of Slave & & \\
\hline Number of slot & $S_{S}$ & 12 Slots \\
\hline Armature resistance & $R_{a \_} S$ & $2.5 \Omega$ \\
\hline Inductance & $L a \_S$ & $36.7 \mathrm{mH}$ \\
\hline Secondary Mover of Slave & & \\
\hline Number of Magnet & $P_{S^{\prime}}$ & 16 Pieces \\
\hline Number of pole & $P_{S}$ & 16 Poles \\
\hline Pole Pitch & $\tau_{p}$ & $30 \mathrm{~mm}$ \\
\hline Mass of Secondary mover & $M_{S}$ & $9 \mathrm{~kg}$ \\
\hline Length of Secondary mover & & $550 \mathrm{~mm}$ \\
\hline Thrust Constant & $K_{f} S$ & $44.7 \mathrm{~N} / \mathrm{A}$ \\
\hline Induced voltage Constant & $K_{e \_} S$ & $14.9 \mathrm{~V} / \mathrm{m} / \mathrm{s}$ \\
\hline Air-gap & $g$ & $6.0 \mathrm{~mm}$ \\
\hline
\end{tabular}

PI regulator of the speed feedback control of slave was set at the proportional gain $K p \_S=3 \mathrm{As} / \mathrm{m}$ and integration gain $K i \_S=8.5 \mathrm{~A} / \mathrm{m}$. Also, PI regulator of the current feedback control of slave was set at the proportional gain $K p c_{-} S=9.8 \mathrm{Vs} / \mathrm{A}$ and the integration gain Kic_S $=100 \mathrm{~V} / \mathrm{A}$.

Figs. 7-10 show the relationship between command values and the measured values. As a result by using PI control mechanism, it gives the speed command based on the simulated actual speed of the master motor. We noticed that the speed ripple occurs. This time we went the acceleration and deceleration control of up to $0-0.3 \mathrm{~m} / \mathrm{s}, 0-0.5 \mathrm{~m} / \mathrm{s}$. That speed is to follow the command value from the graph. However, it can be seen from the graph is greater amplitude of the current. Slave motor uses a linear guide to the support mechanism of the movable element. That is larger and the amplitude of the current due to the influence of friction is considered.

\section{Conclusions}

The slave motor controlled by PI control, the speed command based on the actual speed of the master motor has confirmed that follow. Next, we will establish a speed delivery method in real-time from the master motor, we would like to clarify the usefulness of parallel synchronous drive in this way. 


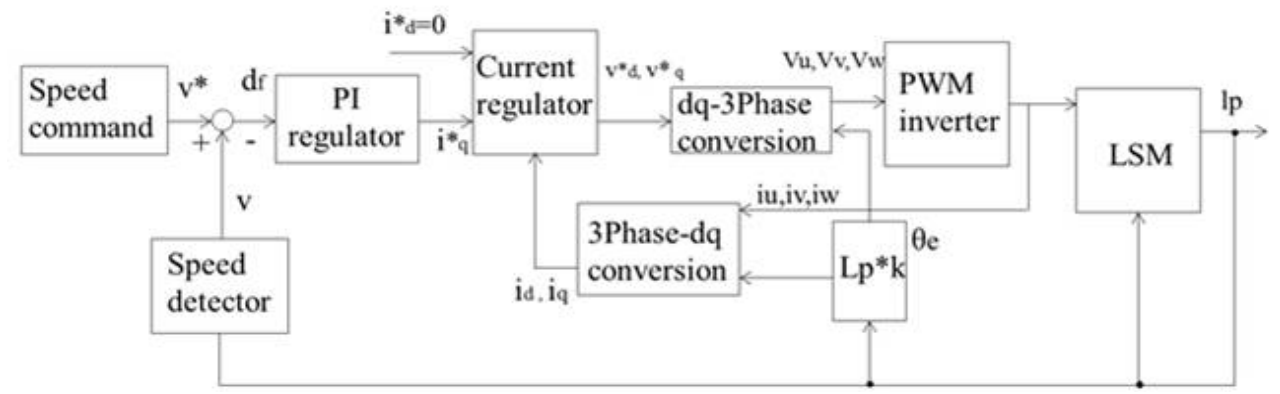

Fig. 6 Block diagram of the PI control of the slave motor.

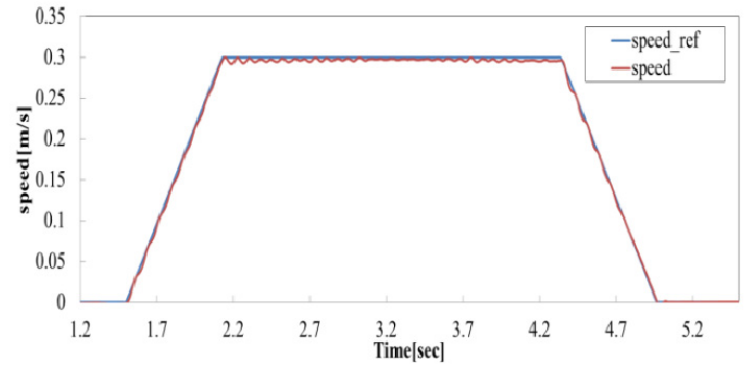

Fig. 7 Speed control results $(0.3 \mathrm{~m} / \mathrm{s})$.

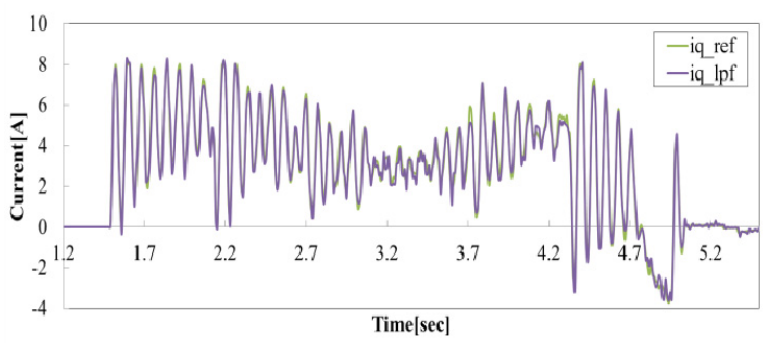

Fig. 8 Current control result $(0.3 \mathrm{~m} / \mathrm{s})$.

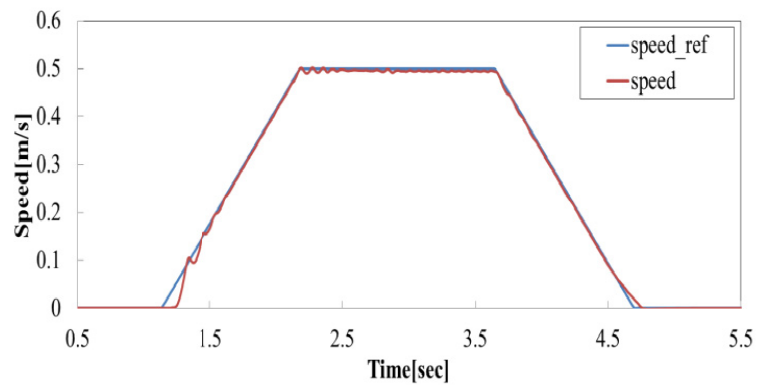

Fig. 9 Speed control results $(0.5 \mathrm{~m} / \mathrm{s})$.

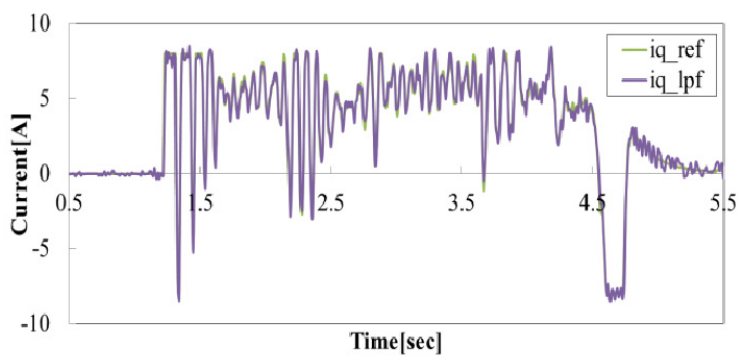

Fig. 10 Current control result $(0.5 \mathrm{~m} / \mathrm{s})$.
In particular, the control system needs to be configured by adding a feed-forward control for compensating the friction.

\section{References}

[1] Azukizawa, T., Morimoto, M., Kanda, S., Tamura, N., and Yokoyama, T. 1989. "A Linear Induction Motor Control System for Magnetically Levitated Carrier System." IEEE Trans. Veh. Technol. 38 (2): 102-8.

[2] Jeon, S., Park, S., and Lee, J. 2006. "Dynamic Characteristics Analysis of 3D Conveyer System Linear Induction Motor for Control Algorithm Developments." Presented at the 12th Biennial IEEE Conf. on Electromagnetic Field Computation, Miami, USA.

[3] Hall, D., Kapinski, J., Krefta, M., and Christianson, O. 2008. "Transient Electromechanical Modeling for Short Secondary Linear Induction Machines." IEEE Trans. Energy Conversion 23 (3): 789-95.

[4] Azukizawa, T. 2003. "Status of Linear Drives in Japan." In Proc. of IEEJ Conf. on Linear Drives for Industry Applications, 12-9.

[5] Seki, K., Watada, M., Torii, S., and Ebihara, D. 1997. "Discontinuous Arrangement of Long Stator Linear Synchronous Motor for Transportation System." In Proc. of IEEE PEDS 97 Conf., 697-702.

[6] Kim, Y. J., Watada, M., Torii, S., and Ebihara, D. 2002. "A Study of the Discontinuous Armature Linear Synchronous Motor in Order to Decrease the Vibration." In Proc. of the International Conference on Electrical Engineering, 908-12.

[7] Kim, Y. J., Dohmeki, H., and Ebihara, D. 2006. "Optimal Driving Method of Stationary Discontinuous Primary PM-LSM by Open-Loop Control." Electric Power Applications 153 (4): 585-91.

[8] Kim, Y. J., and Dohmeki, H. 2007. "Cogging Force Verification by Deforming the Shape of the Outlet Edge at the Armature of a Stationary Discontinuous Armature PM-LSM.” IEEE Trans. Magn. 43 (6): 2540-2.

[9] Suzuki, K., Kim, Y. J., and Dohmeki, H. 2007. "Modeling 
about the Discontinuous Armature Arrangement Interval of the Permanent Magnet Type Linear Synchronous Motor.” In Proc. IEEE Conf. ICEMS 2007, 588-93.

[10] Suzuki, K., Kim, Y. J., and Dohmeki, H. 2008. "Proposal of the Section Change Method of the Stator Block of the Discontinuous Stator Permanent Magnet Type Linear
Synchronous Motor Aimed at Long-Distance Transportation." In Proc. IEEE Conf. ICEM 2008, 1-6.

[11] Suzuki, K., Utiyama, K., Piao, H., and Dohmeki, H. 2014. "Study of Parallel Synchronous Drive Method of Permanent Magnet Linear Synchronous Motor." In Proceedings of APSAEM 2014, 152-3. 